\title{
Power-to-heat in adiabatic compressed air energy storage power plants for cost reduction and increased flexibility
}

\author{
Volker Dreißigacker ${ }^{1}$
}

Received: 23 February 2017 / Accepted: 9 October 2017 / Published online: 23 October 2017

(C) The Author(s) 2017. This article is an open access publication

\begin{abstract}
The development of new technologies for largescale electricity storage is a key element in future flexible electricity transmission systems. Electricity storage in adiabatic compressed air energy storage (A-CAES) power plants offers the prospect of making a substantial contribution to reach this goal. This concept allows efficient, local zero-emission electricity storage on the basis of compressed air in underground caverns. The compression and expansion of air in turbomachinery help to balance power generation peaks that are not demand-driven on the one hand and consumptioninduced load peaks on the other. For further improvements in cost efficiencies and flexibility, system modifications are necessary. Therefore, a novel concept regarding the integration of an electrical heating component is investigated. This modification allows increased power plant flexibilities and decreasing component sizes due to the generated high temperature heat with simultaneously decreasing total round trip efficiencies. For an exemplarily A-CAES case simulation studies regarding the electrical heating power and thermal energy storage sizes were conducted to identify the potentials in cost reduction of the central power plant components and the loss in round trip efficiency.
\end{abstract}

\section{Introduction}

The proportion of electrical energy generated from wind and other renewable sources is set to rise significantly in many

Volker Dreißigacker

volker.dreissigacker@dlr.de

1 German Aerospace Center, Institute of Engineering Thermodynamics, Pfaffenwaldring 38-40, Stuttgart, Germany countries. Whilst it is reasonable to assume a steady evolution in wind turbine capacity, efficiency and reliability, the major obstacles to utilising a high proportion of wind energy lie in its intermittent nature, and its integration into the grid.

The discrepancy in load and generation require a flexibilisation of the electrical energy system that can be achieved using energy storage systems (ESS) [1]. Different technology options are available and well suited for individual tasks due to their storage characteristics, see Fig. 1. Today, high storage capacities and system power respectively are provided by pumped storage power plants (PSPP). This technology is particularly an adequate solution for the large-scale integration of wind energy due to their excellent characteristics for balancing by both extracting from, and supplying electrical energy to the grid. Unfortunately, the capacity of pumped storage power plants is constrained by geography, and in most developed countries there is only limited prospect for further development.

An alternative option with large capacities is given by Compressed Air Energy Storages (CAES) [3-6]. In 1978, a first compressed air energy storage (CAES) plant of $290 \mathrm{MW}$ capacity was built at Huntorf in Germany [7]. In 1991 another 110 MW plant was built in McIntosh, Alabama [8]. Both plants are still in operation today. In periods of low grid load they store electrical energy from base-load power plants or wind farms by means of compressed air. In this process electrically powered turbo-compressors fill underground caverns with compressed atmospheric air. At times of peak load, compressed air is drawn from the cavern, then heated and expanded in a modified gas turbine driving a generator.

The storage efficiency of the diabatic CAES plants is reduced by cooling of the air before it enters the cavern, and by reheating the air prior to burning it with the fuel. Because of this, an adiabatic CAES seeks to overcome these drawbacks, representing a locally emission-free and pure storage 
Fig. 1 Classification of Energy Storage Systems [2]

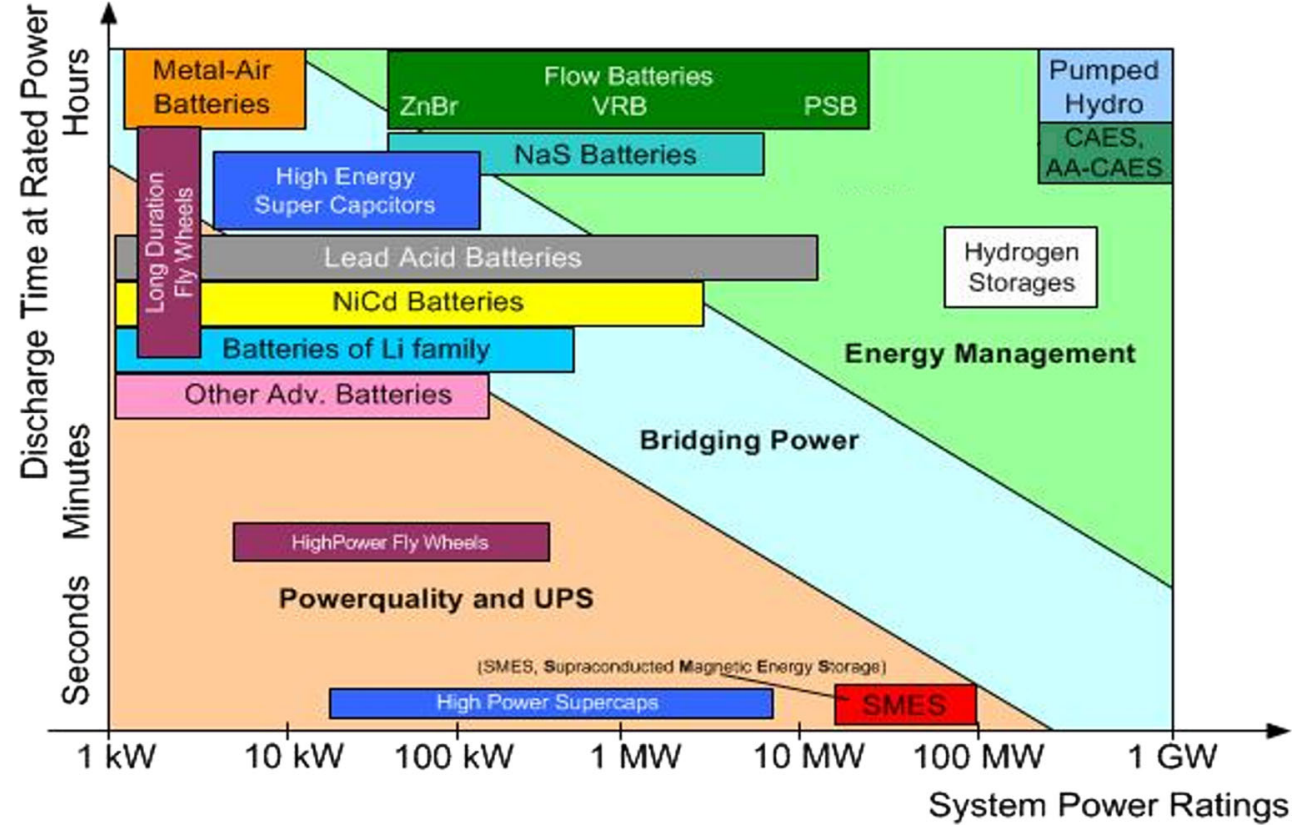

technology. Furthermore, adiabatic compressed air energy storages (A-CAES) already obtain efficiency at 70\% [9] and can therefore already compete with PPSPs.

The basic idea of the A-CAES concept is to use heat storages as a central element of the plant. This allows supplying the heat needed for the expansion process from the otherwise rejected compression heat and thus to avoid a gas combustor. During the charge period the heat is extracted from the air stream and stored. When energy is required by the grid, the compressed air and heat energy is recombined and expanded through an air turbine. Various designs for configuring the compression train have been proposed, including using a series of compression stages to reduce the work of compression [10-13].

The Thermal Energy Storages (TES) are a central element in the design of the power plant and its performance is of decisive importance for the level of efficiency of the overall process. In principle all heat storage technologies that allow minimal losses (in terms of exergy) during heat transmission come into consideration [14]. Since, however, the temperatures at the hot and cold ends of the store are largely determined by the overall process, stores based on sensible media can meet the requirements efficiently. Alternative TES concepts based on phase change materials were investigated by [15] to reduce the amount of entropy generated from the heat exchange process, leading to an improved overall efficiency of the system.

In order to improve the performance of CAES, different system extensions are investigated to utilize the waste heat carried in turbine exhaust during discharge [16] or to allow cooling, heating and electrical generation [17]. An alternative concept based on a conventional A-CAES is focused in this work. Here, system modifications regarding the integration of an electrical heating component are investigated. This novel concept allows decreasing component sizes due to the generated high temperature heat and increased power plant flexibilities with minimal intervention in the power plant configuration.

\section{A-CAES system modification}

To improve the performance and cost efficiency of the adiabatic compressed air energy storage, system modifications of the overall process are investigated. Central idea behind the system modification includes the integration of an electrical heating option to allow more flexibility during charging and to decrease component sizes due to the generation of high temperature heat.

A promising A-CAES power plant is based on a two-stage system with one thermal energy storage systems in the lowpressure (LP) and one in the high pressure range (HP). For both TES systems sensible storage options are used: a regenerator concept with packed beds for the LP-TES and a 2-tank concept with mineral oil for the HP-TES. Based on this original A-CAES system, modifications are investigated regarding an additional electrical heating component in the low pressure area. Figure 2 illustrates the original system and the modification (electrical heating component) with idealized specifications (negligence of pressure drops, temperature losses and component efficiencies). Here, electrical heating 

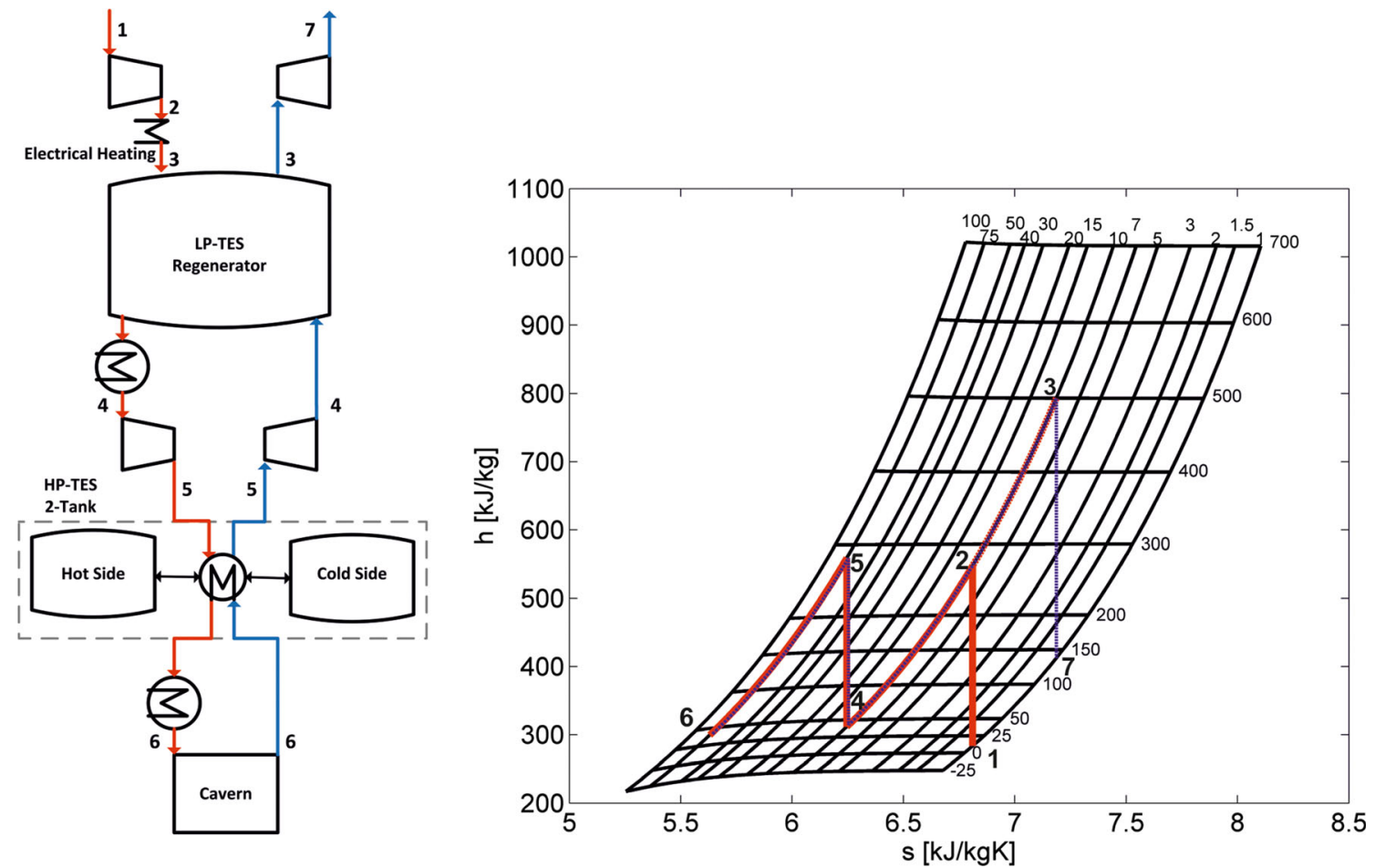

Fig. 2 Function Diagram of the original and modified (electrical heating component in the LP range) two-stage A-CAES (left) and schematic illustration of the storage cycle (right)

temperatures of $500{ }^{\circ} \mathrm{C}$ during charging operation are assumed exemplarily.

During the charging phase adiabatic compressed (2) and electrical heated ambient air (3) passes the LP-TES, where thermal energy is transferred isobaric from the heat transfer fluid to the heat storage system (4). In the second stage the pressurized air is compressed to high pressures (5), cooled down - through transferring heat to the HP-TES system (6) and stored in an underground cavern. Inside the charging procedure safety coolers are integrated after each thermal energy storage system to fulfil the inlet conditions of the HPcompressor and the cavern. During the discharging phase the cold pressurized air is heated up through the thermal energy storage systems and expanded in the turbines.

As seen in Fig. 2 (right) with simplified assumptions, the electrical heating option enables higher storage densities for the LP-TES (3) - thus smaller storage sizes - by increased enthalpy differences, but simultaneously decreasing overall efficiencies due to increasing waste heat temperatures at the outlet of the LP-turbine (7). Additionally, assuming a fix outlet power during discharging, lower mass flow rates are necessary with increasing electrical heating, thus decreasing cavern and turbomachine sizes. This exemplarily illustrated behaviour under idealized specifications show the potential of electrical heating options to improve the cost efficiency and performance.

For the concept under investigation, the integration of the heating component is located in the LP and not in the HP area.
The major advantage, aside from constructive reasons, is thermodynamically based due to the cyclic operation. Assuming the electrical heating component in the HP area, high temperature heat will be generated during charging and stored in the HP-TES. During discharging the heat will be transferred to the cold pressurized air from the cavern, expands through the HPTurbine and enters the LP-TES. With increasing electrical heating the HP-Turbine outlet temperature and LP-TES inlet temperature respectively increases, which lead to two significant drawbacks for the overall system: a reduced utilization of the LP-TES and simultaneously increasing cooling loss through the intercooler. Under extreme conditions - up a distinct amount of heating power - the cold and the hot end of the LP-TES achieve equal inlet temperatures and thus no heat will be stored there. Due to this fact and under a cyclic point of view only electrical heating components in the LP area will be investigated.

\section{Modelling}

For simulation studies of the modified A-CAES concepts, a detailed formulation of the heat storage options is necessary, especially regarding the temporal and spatial characteristics of the LP-TES option based on packed beds. An adequate model for such a regenerator-type solid media heat storage must be used and will be explained in the following. In contrast, the 2tank HP-TES option is mainly determined by the efficiency of 
the heat exchanger with negligible temporal effects. Therefore, the well-known NTU-models can be used, whereat the mass balance of the transported mineral oil between the two containments must be regarded.

With specifying the pressure ratios and isentropic changes in state - in consideration of isentropic coefficients - the outlet temperatures of the turbomachines are calculated. Isothermal conditions, defined by the specified after cooler outlet temperature, are assumed for the cavern. The electrical heating option is modelled in a simple way by assuming an ideal transformation of electrical $\left(P_{\text {Heating }}\right)$ to thermal power $\left(\dot{Q}_{t h}\right)$, which results in a temperature difference $\left(\Delta T_{F}\right)$ for a given mass flow rate $\left(\dot{m}_{F}\right)$ and specific heat capacity $\left(c_{P, F}\right)$ of the fluid $(F)$.

$P_{\text {Heating }}=\dot{Q}_{\text {th }}=\dot{m}_{F} \cdot c_{P, F} \cdot \Delta T_{F}$

A detailed formulation of the electrical heating component is not focused in this work. However, for large-scale applications two promising power to heat technologies are available: inductive and conductive procedures [18, 19]. Both are used in steel industries, where comparable heating powers to the modified A-CAES concept are needed. Technology dependent effects and efficiencies are not considered in this work, but must be regarded in further investigations.

\subsection{LP-TES: solid media}

The thermal model considers the packed bed as heterogeneous porous continuum and provides the temporal and spatial temperature variations of the particles [20]. A well justified simplification is the neglection of radial gradients across the flow direction. The resulting one dimensional heat balances for the fluid and solid phase in time $t$ and space $z$ can be written as.

\section{Fluid}

$$
\begin{aligned}
\varepsilon \rho_{F} c_{F}\left(\frac{\partial T_{F}}{\partial t}+w \frac{\partial T_{F}}{\partial z}\right)= & \lambda_{F, z, \text { eff }} \frac{\partial^{2} T_{F}}{\partial z^{2}} \\
& +k a_{P}\left(T_{S}-T_{F}\right)
\end{aligned}
$$

\section{Solid}

$$
\begin{aligned}
(1-\varepsilon) \rho_{S} c_{S} \frac{\partial T_{S}}{\partial t}= & \lambda_{S, z, e f f} \frac{\partial^{2} T_{S}}{\partial z^{2}} \\
& +k a_{P}\left(T_{F}-T_{S}\right)-k_{W} a_{W}\left(T_{S}-T_{0}\right)
\end{aligned}
$$

where $T_{F}$ and $T_{S}$ are the heat transfer fluid and solid medium temperature, $w$ the fluid velocity, $\varepsilon$ the void fraction, $a_{P}$ and $a_{W}$ the volume specific heat transfer surface for the particle inventory and the surrounding containment walls respectively, defined by the particle diameter $d_{P}$ and the containment diameter $D$. The total heat transfer coefficient $k$ for regenerator-type solid media heat storages regarding the thermal resistance of the particles is defined by $[21,22]$ and the heat transfer coefficient is given by [23].

Thermal losses are regarded through the insulation by $k_{W}$ and radiation effects between the packed bed and the distributer wall are implemented in the solid boundary conditions. Effective heat conduction coefficients for the fluid $\lambda_{F, z, e f f}$ and solid phase $\lambda_{S, z, \text { eff }}$ are defined by $[24,25]$ as well as temperature dependent material properties for the investigated ceramic particles. Real gas model by Lemmon is used to describe the air properties.

The partial differential equations in (2) and (3) are solved numerically by using a central and a backward finitedifference-method in space for the solid and for the fluid phase respectively. Subsequently, the resulting set of ordinary differential equations is solved in time with a commercial simulation tool (Matlab). The chosen solver type (ode15s) allows high accuracy, a variable time step size and is well suited for stiff equation systems.

\subsection{HP-TES: 2-tank}

The thermal behaviour of the 2-tank storage system is mainly determined by the efficiency of the heat exchanger during transferring heat from the pressurized hot air to the cold mineral oil in charging operation, respectively from the hot mineral oil to the cold pressurized air in discharge operation. With acceptable simplifications - constant material properties, negligence of thermal loss due to moderate temperatures (see Fig. 3, right) and thermal inertia effects inside the heat exchanger during cyclic operation changeover - analytical NTU-models can be used [26, 27]. Therefore, two input parameter are needed: the values of dimensionless temperature change $P_{1}$ and $P_{2}$ and the ratios of heat capacity flows $R_{1}$ and $R_{2}$, where index 1 represents the air and index 2 the mineral

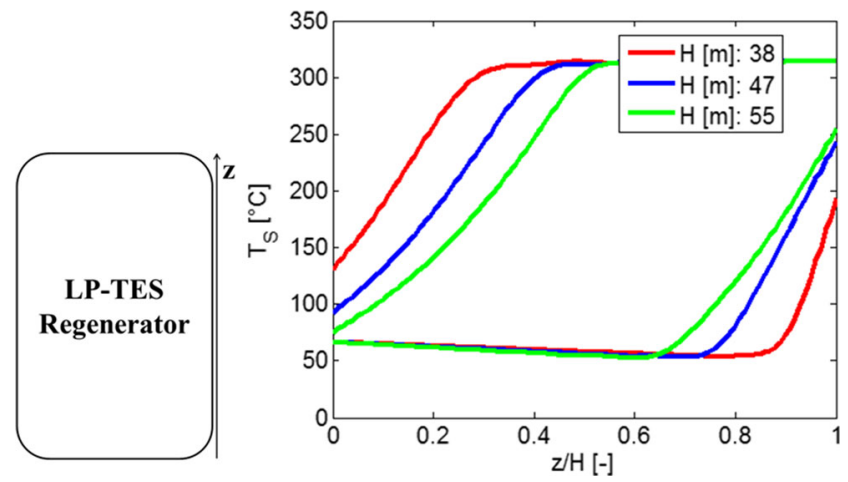

Fig. 3 Spatial solid media temperature profiles at the end of charging and discharging for the LP-TES in the thermal cyclic equilibrium for three different bed heights 
oil. Considering the cyclic operation, two sets of $P_{i}$ and $R_{i}$ for charging and discharging are required.

Due to the condition of a constant cold $\left(T_{2, \text { cold }}\right)$ and hot temperature $\left(T_{2, h o t}\right)$ in the 2-tank storage system over the thermal cycles, two additional equations are given by:

$$
\begin{aligned}
& T_{2, \text { charge }}^{\text {in }}=T_{2, \text { discharge }}^{\text {out }}=T_{2, \text { cold }} \\
& T_{2, \text { charge }}^{\text {out }}=T_{2, \text { discharge }}^{\text {in }}=T_{2, \text { hot }}
\end{aligned}
$$

Assuming further an idealized heat exchanger in counter flow with a ratio of heat capacity flow equal one $\left(R_{1}=R_{2}=1\right)$ and equal charging-discharging durations, thus equal values of dimensionless temperature change for charging and discharging $\left(P_{\text {charge }}=P_{\text {discharge }}=P\right)$, the cold an hot temperature of the 2-tank storage system as well as the size of the heat exchanger (NTU) can be calculated through:

$$
\begin{aligned}
& T_{2, \text { hot }}=\frac{T_{1, \text { charge }}^{\text {in }}+T_{1, \text { discharge }}^{\text {in }} \cdot(1-P)}{2-P} \\
& T_{2, \text { cold }}=T_{2, \text { hot }}-P \cdot\left(T_{2, \text { hot }}-T_{1, \text { discharge }}^{\text {in }}\right) \\
& N T U=\frac{P}{1-P}
\end{aligned}
$$

Additionally, in consideration of the mass balance, the ratio of heat capacity flow during charging and discharging operation must be equal $\left(R_{\text {charge }}=R_{\text {discharge }}\right)$.

With this set of equations and assumptions, the outlet temperatures of the mineral oil as well as of the pressurized air and the size of the heat transfer exchanger are determined by a given value $P$ and the air inlet temperatures $T_{1, \text { charge }}^{\text {in }}$ and $T_{1, d i s c h a r g e}^{i n}$ resulting from the cyclic system operation.

\section{Results}

The aim of the system modifications are to identify suitable combinations of heat storage sizes and electrical heating powers to allow a reduction of component sizes (TES, turbomachines, cavern) with passable lost in the overall system efficiency. Therefore, the thermal equations described in chapter 3 are solved numerically. Inside the unsteady calculation procedure, an iterative adaption of the temporal discharging mass flow rate and the constant charging mass flow rate are performed to achieve constant turbine outlet powers and to fulfil the criterion of balanced air mass inside the cavern. Additionally several cyclic operation runs must be simulated to obtain the thermal cyclic equilibrium inside the LP-TES resulting in temporal constant thermal outlet characteristics.

To identify suitable design modifications, a set of characteristic boundary conditions for a large scale A-CAES power plant must be defined firstly (Table 1 ).

Here, pressure drops for the TES, the heat exchangers and the piping are neglected, but regarded for the cavern (2 bar assumed). The outlet temperatures of the integrated safety coolers (4 and 6 in Fig. 2) are set to a value of $40{ }^{\circ} \mathrm{C}$.

Additional further parameters regarding the central components are defined. Here, isentropic coefficients for the turbomachines are set to a value of 0.86 and the inlet temperature of the ambient air is defined by $10{ }^{\circ} \mathrm{C}$. Ceramic material properties are assumed for the packed bed in the LP-TES with particle diameters of $0.03 \mathrm{~m}$, a void fraction of $40 \%$ and a bed diameter of $10 \mathrm{~m}$. The Insulation thickness of the surrounding containment walls is defined by a value of $0.5 \mathrm{~m}$ with a heat conductivity of $0.5 \mathrm{~W} / \mathrm{mK}$. Emission coefficients regarding the thermal radiation loss between the packed bed and the distributor walls are set to a value of 0.7. Finally, the dimensionless temperature change $P$ for the 2-tank HP-TES is given to a value of 0.85 .

Following, simulation results are presented relating to variation studies of the LP-TES height and the electrical heating power (2-3 in Fig. 2). Therefore, a constant and fix discharging electrical output power of $65 \mathrm{MW}_{\mathrm{el}}$ is assumed with charging and discharging durations of each $6 \mathrm{~h}$ respectively and a stand still period after discharging of $12 \mathrm{~h}$ to fulfil a daily cycle.

\subsection{Variation studies without electrical heating}

First simulation results in Figs. 3 and 4 for the thermal cyclic equilibrium without electrical heating during charging operation are presented. Central effects on spatial and temporal characteristics for different packed bed heights and the specified condition of constant outlet power are explained.

Regarding the influence of the packed bed height $(H)$ of the LP-TES, solid media spatial temperature profiles $\mathrm{T}_{\mathrm{S}}$ at the end of charging and discharging are shown in Fig. 3.

The results illustrated in a normalized bed height $(\mathrm{z} / \mathrm{H})$ depict an increased LP-TES utilization with decreasing bed sizes, thus an increased storage density. As a consequence, the hot and cold ends at the top and the bottom of the LPTES see higher temperature changes, accordingly a lower
Table 1 Boundary conditions for turbomachines (Fig. 2)

\begin{tabular}{llll}
\hline LP-Comp. Press. (1-2) & HP-Comp. Press. (4-5) & LP-Turb. Press. (3-7) & HP-Turb. Press. (5-4) \\
\hline $1-10 \mathrm{bar}$ & $10-(60 \rightarrow 75)$ bar & $10-1 \mathrm{bar}$ & $(71 \rightarrow 56)-10 \mathrm{bar}$ \\
\hline
\end{tabular}



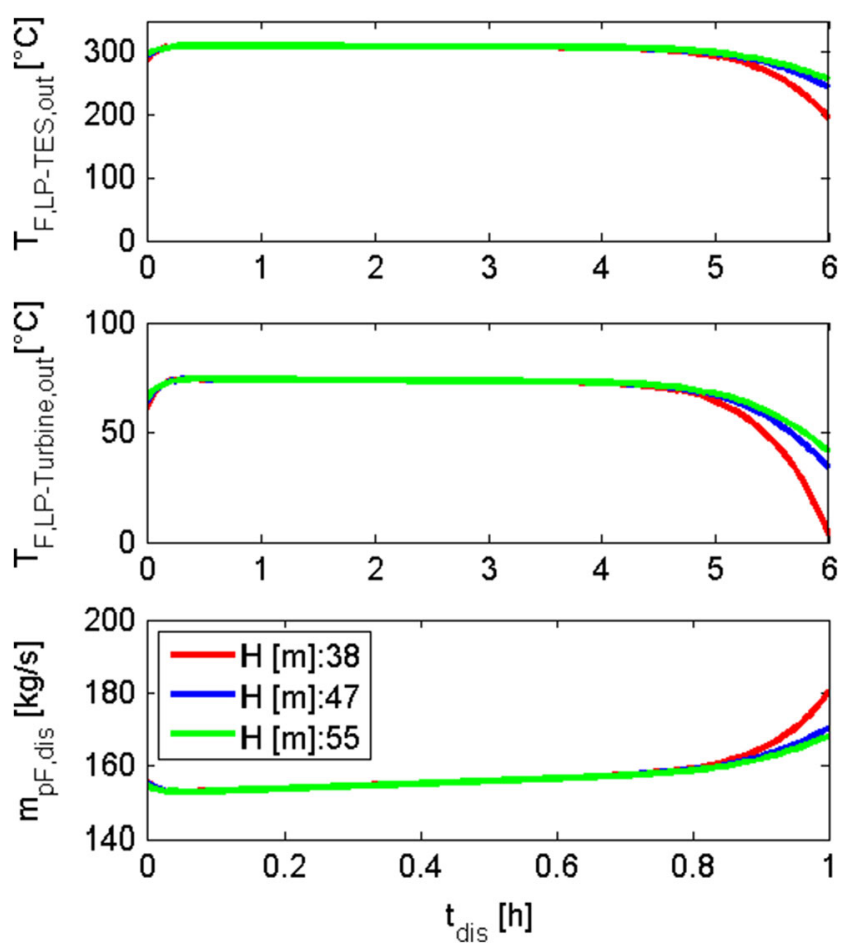

Fig. 4 Temporal characteristics during discharging: LP-TES fluid outlet temperature (top), LP-turbine outlet temperature (middle) and mass flow rate (bottom)

uniformity in the outlet temperatures. The results show a significant potential to decrease storage masses with comparable amounts of stored thermal energy up to a distinct limit mainly determined by the temperature spreads at the hot end of the bed and the condition of constant outlet power.

This context is shown in Fig. 4 by illustration the temporal temperature characteristics during discharging at the outlet of the LP-TES $\left(\mathrm{T}_{\mathrm{F}, \mathrm{LP} \text {-TES,out }}\right)$, at the outlet of the low-pressure turbine $\left(\mathrm{T}_{\mathrm{F}, \mathrm{LP} \text {-Turbine,out }}\right)$ as well as the corresponding discharging mass flow rate $\left(\mathrm{m}_{\mathrm{pF}, \mathrm{dis}}\right)$.

As seen in Fig. 4 (top), decreasing storage heights lead to the mentioned increased temperature spread at the end of discharging. For a bed height of $55 \mathrm{~m}$ outlet fluid temperatures at the end of discharging of $250^{\circ} \mathrm{C}$ are calculated, whereas for a bed height of $38 \mathrm{~m}$ a higher temperature drop at $200{ }^{\circ} \mathrm{C}$ is achieved. Analogical, this context is visible at the outlet of the LP-turbine (Fig. 4, middle) after expansion, where $10^{\circ} \mathrm{C}$ at the end of discharging are reached in case of $38 \mathrm{~m}$ bed height. Fulfilling the condition of constant outlet power during discharging, the temperature drop at the LP-turbine must be balanced through a temporal increasing mass flow rate (Fig. 4, bottom).

The results in Fig. 4 show the restrictions regarding the reduction of the bed height. With further decreasing the storage heights, LP-turbine outlet temperatures less than $0{ }^{\circ} \mathrm{C}$ will be reached and an increased mass flow rate at the end of discharging is necessary. Both effects lead to significant risks in the LP-turbine operation and thus in a limitation of the bed heights. To overcome these restrictions, simulation results with electrical heating will be presented in the following.

In contrast to the LP-TES with variation studies regarding the bed height, fixed thermal boundary conditions and specifications are defined for the 2-tank HP-TES with mineral oil. Therefore, storage masses of $1580 \mathrm{t}$ are needed with negligible impacts through the varying temporal averaged discharging flow rates (see Fig. 4 bottom).

\subsection{Variation studies with electrical heating}

To allow further reductions of the LP-TES heights as well as the component sizes of the HP-TES, turbomachines and cavern, simulation results with electrical heating during charging are shown. As illustrated in Fig. 2 (right), an additional electrical heating during charging operation opens up the potential to decrease component sizes by generation of high temperature heat, but lead simultaneously to decreasing overall efficiencies $\left(\eta_{\text {tot }}\right)$ due to increased waste heat.

This effect is illustrated in Fig. 5 with variations of heating temperatures between $350{ }^{\circ} \mathrm{C}$ and $550{ }^{\circ} \mathrm{C}$ and bed heights. The results for the pure adiabatic condition with zero electrical heating (blue line) was explained in chapter 4.1.

With increasing electrical heating and decreasing bed heights, the overall efficiency decreases. For the variation case without electrical heating overall efficiencies of about $72 \%$ are achieved, whereas the lower limit in bed height is determined through the increased temperature spread at the hot end of the LP-TES (see Fig. 4). Comparable results are visible for cases with electrical heating. Here, significant lower bed heights up to $28 \mathrm{~m}$ compared to the pure adiabatic cases $\left(\mathrm{P}_{\text {Heat }}=0\right)$ are possible due to higher thermal storage densities, but at the same time a decrease in the overall efficiency up to $62 \%$.

Beside the potential to reduce TES dimensions, the generated high temperature heat leads to a decrease of the compressors and cavern size. To illustrate this behaviour (Fig. 6), the

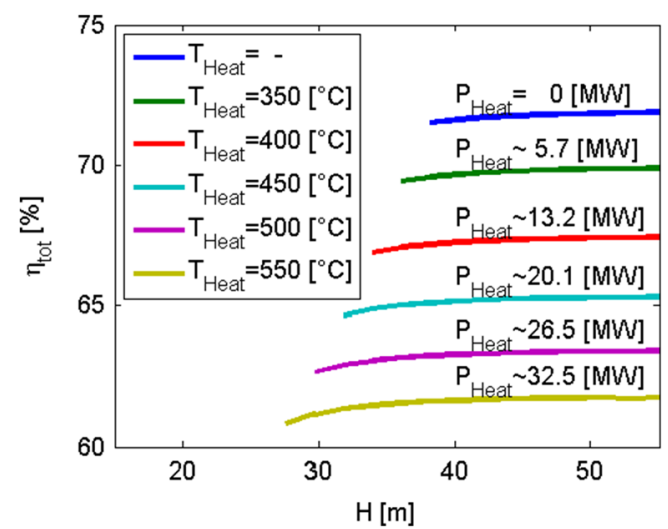

Fig. 5 Total round trip efficiency versus feasible LP-TES bed heights for different electrical heating temperatures and powers 


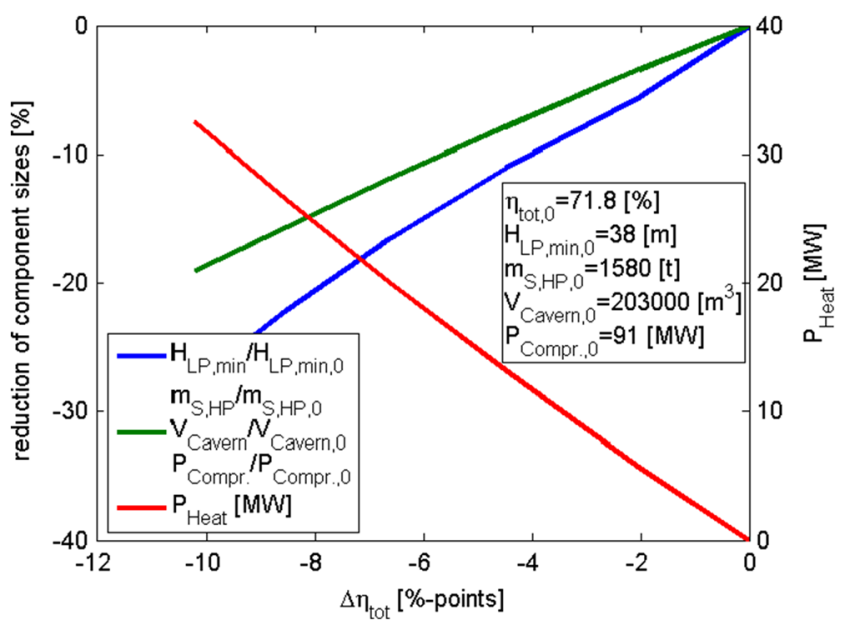

Fig. 6 Electrical heating powers and relative reduction of component sizes related to the reference case versus loss in round trip efficiency

results are presented in the loss of the overall efficiency $\Delta \eta_{\text {loss }}$ in relation to the electrical heating power $\mathrm{P}_{\text {Heat }}$ and the relative reduction of component sizes related to a reference case without electrical heating (index 0 ). The value $\mathrm{H}_{L P \text {,min }}$ represents the lowest feasible LP-TES dimension, where LP-turbine outlet temperatures of $10{ }^{\circ} \mathrm{C}$ are achieved (compare Fig. 4 middle).

The results of the relative LP-TES size $\mathrm{H}_{\mathrm{LP}, \min } / \mathrm{H}_{\mathrm{LP}, \min , 0}$ show a reduction of up to $26 \%$ by a simultaneously decrease in the overall efficiency of $10 \%$ related to the reference case, whereas heating powers of $32.5 \mathrm{MW}$ are necessary (see results in Fig. 5). Aside from this effect, a reduction of the HP-TES mineral oil storage mass $\mathrm{m}_{\mathrm{S}, \mathrm{HP}}$, the cavern size $\mathrm{V}_{\mathrm{Cavern}}$ and the compressor power $\mathrm{P}_{\mathrm{Compr}}$ of about $19 \%$ is achieved. Here, for the maximum electrical heating power of $32.5 \mathrm{MW}$ the HPTES storage mass is reduced to $1280 \mathrm{t}$ compared to the nonheated case with $1580 \mathrm{t}$.

This behaviour is caused by the higher LP-TES thermal storage densities through the electrical heating option and thus lower discharging mass flow rates to generate the defined outlet power of $65 \mathrm{MW}_{\mathrm{el}}$. As a result, smaller HP-TES dimensions, compressor powers as well as lower cavern volumes are required and lead besides the reduced LP-TES size to a significant potential in cost reduction.

\section{Conclusions}

The grid-compatible expansion of renewable, fluctuating energy sources makes it necessary to provide sufficient electricity storage capacity. Adiabatic compressed air energy storage power plants are a promising option here with high expansion potential.

For further improvements in cost efficiency and flexibilisation, a novel system modification in a 2 -stage CAES power plant through the integration of an electrical heating component in the low pressure area is investigated. The results confirm a significant potential to decrease the central component sizes of the heat storages, the compressors and cavern due to the generated high temperature heat by simultaneously decreased total round trip efficiencies. Exemplarily, the results for the investigated power plant case with discharging capacities of $390 \mathrm{MWh}_{\mathrm{el}}$ show with a moderate reduction of the total round trip efficiencies related to the pure adiabatic operation without electrical heating, a potential to decrease component sizes up to $10 \%$. Besides significant improved cost efficiency, an increased flexibility can be achieved through the electrical heating option by the fast generation and storage of the high temperature heat. Thus additionally markets will be opened and an increased economic efficiency for this technology is achieved.

In further works, the identification and development of the electrical heating component with heating powers in a range between $5 \mathrm{MW}_{\mathrm{el}}$ to $20 \mathrm{MW}_{\mathrm{el}}$ are necessary. Promising industrial power to heat technologies are available (inductive and conductive procedures), but must be adapted for CAES applications. One adequate solution includes an inductive heating of metallic rods, in which the heat is transferred to the passing air in direct contact. This option allows a contactless electric heating procedure with high charging powers up to high temperature ranges. For this purpose, simulation models are formulated regarding geometric aspects and material characteristics to identify high efficient and flexible designs.

Acknowledgements The authors gratefully acknowledge the Federal Ministry of Economics and Technology (BMWi) for its support of this article by funding the project ADELE-ING (project reference number: 03ESP144F).

Open Access This article is distributed under the terms of the Creative Commons Attribution 4.0 International License (http:// creativecommons.org/licenses/by/4.0/), which permits unrestricted use, distribution, and reproduction in any medium, provided you give appropriate credit to the original author(s) and the source, provide a link to the Creative Commons license, and indicate if changes were made.

\section{References}

1. Vazques S, Lukic S, Galvan E, Franquelo L (2010) Energy Storage Systems for Transport and Grid Applications. IEEE Trans Ind Electron 57(12):3881-3895

2. Styczynski Z, Lombardi P et al (2011) Electric energy storage systems. Electra 255, CIGRE, Paris

3. Zhang Y, Yang K, Li X, Xu J (2013) The thermodynamic effect of thermal energy storage on compressed air energy storage system. Renew Energy 50:227-235

4. Lund H, Salgi G (2009) The role of compressed air energy storage (CAES) in future sustainable energy systems. Energy Convers Manag 50:1172-1179

5. Najjar YS, Zaamout MS (1998) Performance analysis of compressed air energy storage (CAES) plant for dry regions. Energy Convers Manag 39:1503-1511 
6. Liu JL, Wang JH (2016) A comparative research of two adiabatic compressed air energy storage systems. Energy Convers Manag 108:566-578

7. Crotogino F, Mohmeyer KU, Scharf R (2001) Huntorf CAES: More than 20 Years of Successful Operation. Proc of SMRI Spring Meeting, Orlando, Florida, USA, 15-18 April

8. Holden P, Moen D, DeCorso M, Howard J (2000) Alabama electric cooperative compressed air energy storage (CAES) plant improvements. https://doi.org/10.1115/2000-GT-0595

9. Hartmann N, Vöhringer O, Kruck C, Eltrop L (2012) Simulation and analysis of different adiabatic Compressed Air Energy Storage plant configurations. Appl Energy 93:541-548

10. Kim YM, Lee JH, Kim SJ, Favrat D (2012) Potential and evolution of compressed air energy storage: energy and exergy analyses. Entropy 14(8):1501-1521

11. Grazzini G, Milazzo A (2008) Thermodynamic analysis of CAES/ TES systems for renewable energy plants. Renew Energy 33(9): 1998-2006

12. Grazzini G, Milazzo A (2012) A thermodynamic analysis of multistage adiabatic CAES. Proc IEEE 100(2):461-472

13. Wolf D, Budt M (2014) LTA-CAES e a low-temperature approach to adiabatic compressed air energy storage. Appl Energy 125:158164

14. Turner RH (1978) High temperature thermal energy storage. Franklin, Philadelphia

15. Tessier MJ, Floros MC, Bouzidi L, Narine SS (2016) Exergy analysis of an adiabatic compressed air energy storage system using a cascade of phase change materials. Energy 106:528-534

16. Pan Z, Yiping D, Jiangfeng W (2015) Performance assessment and optimization of a combined heat and power system based on compressed air energy storage system and humid air turbine cycle. Energy Convers Manag 103:562-572

17. Song L, Wei H, Aifeng Z, Guiqiang L, Bingqing L, Xianghua L (2017) Modelling and analysis of a novel compressed air energy storage system for trigeneration based on electrical energy peak load shifting. Energy Convers Manag 135:394-401

18. Lucía O, Maussion P, Dede EJ, Burdío JM (2014) Induction heating technology and its applications: past developments, current technology, and future challenges. IEEE Trans Ind Electron 61(5):25092520

19. Sterner M, Stadler I (2014) Energiespeicher. Bedarf, Technologien, Integration. Springer Vieweg, Berlin, Heidelberg

20. Ismail KAR, Stuginsky R (1999) A parametric study on possible fixed bed models for $\mathrm{pcm}$ and sensible heat storage. Appl Therm Eng 19:757-788

21. Hausen H (1950) Wärmeübertragung im Gegenstrom, Gleichstrom und Kreuzstrom. Springer, Heidelberg, Berlin

22. Schmidt FW, Willmott AJ (1981) Thermal energy storage and regeneration. New York, McGraw-Hill Book Company

23. Gnielinski V (1982) Berechnung des Wärme- und Stoffaustauschs in durchströmten ruhenden Schüttungen. Verfahrenstechnik 16(1): 36-39

24. Wakao N, Kaguei S (1982) Heat and mass transfer in packed beds. Gordon and Braech, New York

25. Bauer R, Schlünder EU (1978) Effective radial thermal conductivity of packings in gas flow. Part II: Thermal conductivity of the packing fraction without gas flow. Int Chem Eng 18:189-204

26. Martin H (1988) Wärmeübertrager. Thieme, Stuttgart, New York

27. Shah RK, Sekulić DP (2003) Fundamentals of heat exchanger design. John Wiley \& Sons, Inc., Hoboken 